\title{
Prevalence of intestinal parasites among captive Asian Elephants Elephas maximus: effect of season, host demography, and management systems in Tamil Nadu, India
}

\author{
V. Vanitha ${ }^{1}$, K. Thiyagesan ${ }^{2} \&$ N. Baskaran ${ }^{3}$ \\ 1,2 Postgraduate and Research Department of Zoology and Wildlife Biology, A.V.C. College, Mannampandal, Mayiladuthurai, Tamil \\ Nadu 609305, India. \\ ${ }^{3}$ Asian Nature Conservation Foundation, Innovation Centre, Indian Institute of Science, Bengaluru, Karnataka 560012 India \\ Present address: ${ }^{1}$ D.G. Government Arts College (Women), Mayiladuthurai, Tamil Nadu 609001, India. \\ Email: ${ }^{1}$ vanithabaskar@rediffmail.com (corresponding author), ${ }^{2}$ kthiyagesan1@rediffmail.com, ${ }^{3}$ baskar@ces.iisc.ernet.in
}

Date of publication (online): 26 February 2011 Date of publication (print): 26 February 2011 ISSN 0974-7907 (online) | 0974-7893 (print)

Editor: Heidi S. Riddle

\section{Manuscript details:}

Ms \# 02488

Received 21 June 2010

Final received 02 January 2011

Finally accepted 17 January 2011

Citation: Vanitha, V., K. Thiyagesan \& N Baskaran (2011). Prevalence of intestinal parasites among captive Asian Elephants Elephas maximus: effect of season, host demography, and management systems in Tamil Nadu, India. Journal of Threatened Taxa 3(2): 1527-1534.

Copyright: (c) V. Vanitha, K. Thiyagesan \& N Baskaran 2011. Creative Commons Attribution 3.0 Unported License. JoTT allows unrestricted use of this article in any medium for non-profit purposes, reproduction and distribution by providing adequate credit to the authors and the source of publication.

Author Details \& Acknowledgements: see end of this article.

Author contribution: VV designed and conducted the present study as a part of her Doctor of Philosophy Research Degree. KT and NB supervised the research work with technical inputs as research advisers.

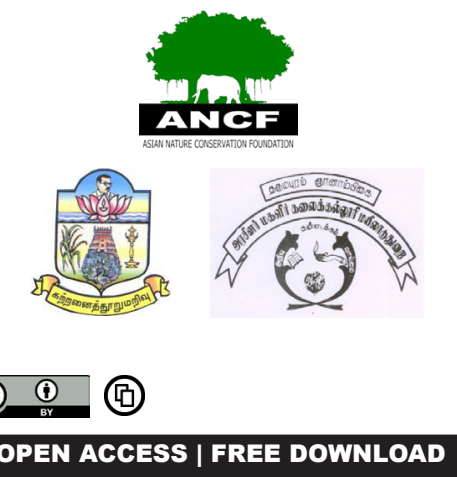

Abstract: Maintenance of wild animals in captivity is fraught with numerous challenges, including the control of disease. This study evaluates the effect of season, host demography (age-sex), and differing management systems on the prevalence of intestinal parasites among elephants managed in three captive systems: temple, private, and forest department, in Tamil Nadu. In addition, the study also assessed the availability of veterinary care for elephants in these systems. The parasitic prevalence was evaluated by direct microscopic identification of helminth eggs in faecal samples ( $n=115$ ) collected from different age/sex classes of elephants. Of the 115 elephants examined, $37 \%$ showed positive results, being infected only with Strongyles sp. The prevalence rate varied significantly across seasons, with the highest rate during summer $(49 \%)$ followed by monsoon (41\%) and the lowest rate during winter $(15 \%)$. While males had a significantly lower parasite prevalence compared to females (29\% vs. $40 \%$ ), age classes showed no significant difference. Despite the fact that the proportion of animals receiving veterinary care was higher under the forest department system $(100 \%)$ compared to the private system $(26 \%)$, parasite prevalence was significantly higher under the former $(48 \%)$ than the latter $(31 \%)$ system. The difference in the proportion of animals with parasitic prevalence among the three systems could be due to differing management practices (i.e. in solitary versus groups) and the details are discussed.

Keywords: Captive Asian Elephants, forest department, intestinal parasite, management prevalence, private, Temple.

\section{INTRODUCTION}

Most free-living organisms harbour parasites of several species (Begon \& Bowers 1995), which can adversely affect host health, fecundity and foraging, and may also modify host behaviour to facilitate parasite transmission (Wesenberg-Lund 1931; Holmes \& Bethel 1972; Moore 1984). Parasitism has been shown to directly affect both the evolution and ecology of hosts through processes such as sexual selection (Hamilton \& Zuk 1982) or parasite-mediated competition, which can lead to a reduction in population size, or the extinction of one host (Price et al. 1986). Asian Elephants Elephas maximus are susceptible to gastrointestinal parasitic infection in the wild (Watve 1995; Dharmarajan 2000; Vidya \& Sukumar 2002) and in captivity are often confined to small enclosures and/or maintained in isolation (Vanitha 2007) in damp unhygienic conditions that may result in enhanced susceptibility to parasitic disease (Dhungel et al. 1990; Chandrasekaran et al. 1995; Suresh et al. 2001).

Tamil Nadu, a southern state of India, manages approximately 150 
captive elephants under three different management systems: private, temple and forest department (Vanitha 2007; Vanitha et al. 2010). The captive elephants in the temple system are managed with very limited mobility and are used mainly for religious and cultural ceremonies in Hindu temples, while private elephants are used for commercial purposes such as in films and in VIP programmes with extensive travel, in addition to cultural and religious ceremonies in Hindu temples that do not own an elephant. In contrast, captive elephants in the Tamil Nadu forest department are managed mostly in semi-wild conditions at forest camps located in Mudumalai and Anamalai wildlife sanctuaries (presently tiger reserves). While originally used for timber logging, captive elephants under the forest department management are presently used predominantly for ecotourism. Additionally, on a rotational basis, a few elephants from the timber camps are placed by the forest department at the Arignar Anna Zoological Park, Chennai, for education and entertainment (Vanitha et al. 2010).

Given the widely differing husbandry conditions in which elephants are managed under the three systems (Vanitha 2007; Vanitha et al. 2008, 2009), it is meaningful to ask whether there is variability in the prevalence of parasites in the different management systems. There have been studies on the prevalence of parasitic infection in captive elephants managed in nature reserves (Arunachalam et al. 2007), zoological gardens (Suresh et al. 2001) and Hindu temples (Saseedran et al. 2003). This paper presents data comparing the occurrence of intestinal parasites among captive elephants in three management systems during various seasons and among various age-sex classes in Tamil Nadu.

\section{MATERIALS AND METHODS}

Study animals and samplingprocedures: Between 2003 and 2005, faecal samples (one/individual) were collected from 115 captive elephants managed by: (i) the Tamil Nadu Forest Department at the elephant camps in Mudumalai and Anamalai wildlife sanctuaries, and Arignar Anna Zoological Park, Vandalur $(n=42)$, (ii) temples ( $\mathrm{n}=38$ : Appendix 1), and (iii) private owners $(\mathrm{n}=35$ : Appendix 2). Dung samples were collected within a few hours of defecation and stored in $10 \%$ formalin. From each dung pile, a representative sample was collected from the outer and inner parts of different boli; parts in contact with soil were avoided. Details of the age and sex of the study animals were recorded by interviewing the mahouts (keepers) as well as by verifying the studbook or register of records. Where proper age records were not available, as in the case of animals caught/rescued from the wild by the forest department or those bought from other states by private and temple authorities, age was estimated by employing the shoulder height method of Sukumar et al. (1988). Considering the diverse climatic conditions that prevail across the study area: the Western Ghats, where the forest department manages most of its captive elephants, and the plains, where the private and temple systems manage their elephants, the year was divided into three seasons - summer, monsoon, and winter and designated according to similarities in climate. For the timber camps of the forest department, the period from February to April was treated as summer, May to November as monsoon, and December to January as winter. In the case of private, temple and Arignar Anna Zoological Park elephants, March to July was classified as summer, August to November as monsoon, and December to February as winter.

Parasite prevalence appraisal: The prevalence of intestinal parasites among captive elephants was assessed through coprological analysis using direct microscopic examination, and the sedimentation floatation methods following Watve (1992, 1995), Vidya \& Sukumar (2002), and the sedimentation technique standardized by Monson-Bhar \& Bell (1982). In the sedimentation floatation method, a known weight of dung sample (in 10\% formalin) was strained to remove the coarse debris and the filtrate was centrifuged. The dung that sedimented was dissolved in $10 \mathrm{ml}$ of saturated zinc sulphate solution (specific gravity $1.8 \%$ ) and centrifuged again. In the first centrifugation, nematode eggs sink with the faecal matter. Nevertheless, in the second round they float to the surface due to the high specific gravity of zinc sulphate. Six loopfuls of the solution were removed from the surface using a wire-loop of $5 \mathrm{~mm}$ diameter and the solution was examined to record presence or absence of eggs. If no eggs were found in a sample, 12 more loopfuls of the solution (six at a time) were scanned for eggs to confirm the absence of parasite infection. In the sedimentation technique (Monson- 
Bhar \& Bell 1982), a small amount of faecal sample was emulsified with $10 \mathrm{ml}$ of water in a centrifuge tube and was centrifuged for two minutes at 3000rpm. The supernatant was poured off carefully and a drop of the sediment was placed on a slide and examined under the microscope.

Veterinary care: The availability of professional veterinarycare for the elephants in the threemanagement systems was evaluated through a questionnaire survey with the concerned authorities, and also by scrutinizing the register (medical) records of the elephants. Information such as presence or absence of periodic medical check-ups by veterinarians, and the number of medical check-ups per year were obtained for each elephant.

Analysis: The prevalence of parasitic infection among captive elephants in three management systems, three seasons, and different sex and age-classes was determined by the presence or absence of data on parasitic infection of individual elephants. Statistical significance for the proportion of elephants infected with parasites out of the total number of individuals examined was tested using the proportion test. A logistic regression analysis using presence or absence of parasites (coded as 1 or 0 ) at the individual level as the independent variable, and the management system (private, temple, forest department), season (monsoon, summer, winter), age class (calf \& juvenile (0-5 yr), sub-adult (5-15 yr), adult (15 yr and above)) and sex (male, female), as dependent variables were coded as 1 to 2 or 3 according to number of categories. Data on the proportion of elephants with periodic medical check-ups in the three management systems was tested using the proportions test.

\section{RESULTS}

\section{Intestinal parasite prevalence}

Overall and among seasons: Out of 115 individuals examined for intestinal parasite prevalence, 43 (37\%) individuals were found positive (Table 1). All the positive cases were infected only with helminthic parasites (Strongyles sp.). Both eggs and worms of Strongyles sp. were identified from the infected individuals. The eggs were found in all infected cases and worms were found only in one case. The proportion of elephants (43 out of 115) infected
Table 1. Number of elephants examined for prevalence of intestinal parasites and the details of individuals infected in different systems and sexes

\begin{tabular}{|l|c|c|c|c|}
\hline Details & $\begin{array}{l}\text { Forest } \\
\text { Depart- } \\
\text { ment }\end{array}$ & Temple & Private & Overall \\
\hline $\begin{array}{l}\text { Number of individuals } \\
\text { examined }\end{array}$ & 42 & 38 & 35 & 115 \\
\hline $\begin{array}{l}\text { Number of individuals } \\
\text { infected }\end{array}$ & 20 & 12 & 11 & 43 \\
\hline $\begin{array}{l}\text { Number of females } \\
\text { examined }\end{array}$ & 16 & 37 & 31 & 84 \\
\hline $\begin{array}{l}\text { Number of males } \\
\text { examined }\end{array}$ & 26 & 1 & 4 & 31 \\
\hline $\begin{array}{l}\text { Number of females } \\
\text { infected }\end{array}$ & 12 & 12 & 10 & 34 \\
\hline $\begin{array}{l}\text { Number of males } \\
\text { infected }\end{array}$ & 8 & 0 & 1 & 9 \\
\hline
\end{tabular}

with intestinal parasites was significantly lower than uninfected individuals $\left(\chi^{2}=6.817, \mathrm{df}=1, \mathrm{p}=0.009\right)$. Parasite prevalence was significantly different in three seasons (Wald $=9.681, \mathrm{p}<0.01)$ (Table 2), with the highest infection rate found during summer (19 out of 39 or $49 \%$ ), followed by monsoon ( 23 out of 61 or $38 \%$ ), and the lowest infection rate during winter (1 out of 15 or $7 \%$ ). The rate of infection between monsoon and winter did not vary significantly $(\mathrm{B} \pm$ $\mathrm{SE}=2.089 \pm 1.147$, Wald $=3.315, \mathrm{p}>0.05$ ), while the infection rate between summer and winter varied statistically $(\mathrm{B} \pm \mathrm{SE}=3.238 \pm 1.169$, Wald $=7.670$, $\mathrm{p}<0.01$ ), indicating parasite prevalence was more common during summer.

Prevalence among three management systems: The occurrence of intestinal parasites varied significantly among the three management systems (Wald $=8.753, p=0.01)$ with the prevalence of parasite infection being higher among captive elephants in the forest department ( 20 out of 42 or $48 \%$ ) system than in temple (12 out of 38 or $32 \%$ ) and private (11 out of 35 or $31 \%$ ) systems (Table 1). The proportion of infected individuals between the private and forest department systems was not significantly different $(\mathrm{B} \pm \mathrm{SE}=-1.300$ \pm 0.697 , Wald $=3.483, p>0.05)($ Table 2$)$, while the infection rate observed between the temple and forest department systems showed a significant difference $(\mathrm{B} \pm \mathrm{SE}=-2.239 \pm 0.757$, Wald $=8.750, \mathrm{p}<0.01)$ indicating a higher susceptibility to parasitic diseases for elephants in the forest department system. 
Table 2. Results of logistic regression analyses carried out to test the significance of intestinal parasite prevalence among systems, seasons, age-classes and between sexes

\begin{tabular}{|c|c|c|c|}
\hline Variables & Coefficient \pm SE & Wald & P level \\
\hline Between systems: Temple / Forest Department & $-2.239 \pm 0.757$ & 8.750 & 0.003 \\
\hline Among seasons: monsoon $(n=61)$, summer $(n=39)$ and winter $(n=15)$ & - & 9.681 & 0.008 \\
\hline Between seasons: summer / winter & $3.238 \pm 1.169$ & 7.670 & 0.006 \\
\hline Among age-classes: calf and juvenile $(n=8)$, sub-adult $(n=21)$ and adult $(n=86)$ & - & 1.221 & 0.543 \\
\hline Between age-classes: calf and juvenile / adult & $-0.836 \pm 0.922$ & 0.821 & 0.365 \\
\hline
\end{tabular}

Prevalence between sex and among age-classes: Among the 31 males and 84 females sampled, the prevalence of helminthic infection was significantly higher in females (34 out of 84 or $40 \%$ ) than in males ( 9 out of 31 or $29 \%),(\mathrm{B} \pm \mathrm{SE}=-1.693 \pm 0.649$, Wald $=6.811, \mathrm{p}<0.01)($ Table 2) suggesting that females are more prone to helminthic infection under captive conditions than males. Among the three major age classes of elephants tested, the prevalence of intestinal parasites was not significantly different (Wald $=1.221$, $p>0.05$ ) with $41 \%$ individuals in adult class, $29 \%$ of individuals in sub-adult class, and $25 \%$ of juvenile and calves being infected.

Periodic medical care: The data on the veterinary care in the three captive management systems reveal that only one-fourth $(26 \%)$ of the elephants in the private system, and three-fourths (75\%) in the temple system had periodic medical examinations. All the elephants (100\%) in the forest department system were checked periodically by veterinarians. A proportions test on the percentage of elephants with periodical medical check-ups in the three systems reveal that the observed difference was statistically significant $(\mathrm{Z}=$ -2.54; $p<0.01$ ) indicating that in Tamil Nadu elephants managed in the private system had significantly less access to veterinary care than elephants in the other two systems.

\section{DISCUSSION AND CONCLUSIONS}

In general, macroparasites (i.e. parasitic species where reproduction usually occurs via transmission of free-living infective stages that passes from one host to the next) aggregate across their host population with most individuals harbouring low number of parasites, but a few individuals play host to higher parasitic burdens (Shaw \& Dobson 1995). Such heterogeneity is generated due to variation between individuals in their exposure to infective stages and differences in their susceptibility (Wilson et al. 2002). The intestinal parasite Strongyle sp. was prevalent among 37\% of the captive elephants monitored across three management systems in Tamil Nadu during 2003-2005. This parasite infection rate is similar to the prevalence rate of $36 \%$ reported for Mudumalai timber camp elephants (Arunachalam et al. 2007), and lower than that reported (majority of the 245 cases) among the captive elephants in Kerala (Chandrasekharan et al. 1995). However, the present estimate was considerably higher than the $10 \%$ parasite infection reported for the Guruvayoor Temple elephants (Saseedaran et al. 2004). Such differences among different elephant populations could be attributed to variable treatment levels, husbandry practices, sampling season, and agesex classes.

Among the three management systems studied, the parasite prevalence was higher in the captive elephants of the forest department system compared to temple and private systems, while the elephants in the former facility had a higher level of medical attention than 
those in the latter two systems. In the forest department system, over $90 \%$ of the captive elephants are managed at the timber camps in social groups, sharing the natural habitat of wild elephants which are known to have a high parasite prevalence (Watve 1995; Dharmarajan 2000; Vidya \& Sukumar 2002). The social life style, along with the semi-natural environment shared by wild elephants is likely to enhance susceptibility to parasitism from conspecifics both within the system as well as from the wild. In support of this, at the Anamalai timber camp, 14 of the 16 forest department elephants examined for parasites showed positive results. Most of the private and temple elephants are managed in solitary conditions or in small groups, and provided with Astasooranam, a traditional herbal medicine prepared by mahouts, at periodic intervals for digestive ailments (Vanitha 2007). In addition, regular vaccinations and de-worming activities organised by the Tamil Nadu government during the special rejuvenation camps for the temple and private elephants coinciding with this study (2003-2005) may have contributed to the lower prevalence of intestinal parasites among the private and temple elephants. The higher prevalence of helminthic parasite infection during summer and early monsoon could be due to the prevalence of ideal climatic conditions (temperature $\&$ humidity) for faster rates of egg hatching and rapid development to the infective stage as reported elsewhere (English 1979), and due to poor hygienic conditions of the resources such as shelter, food and water. Further, the nutritional state of the host is known to affect immuno-competence (Rolston 1992; Lyles \& Dobson 1993), and as the rainy season progresses, the increased vegetation growth could reduce nutritional stress and thus improve overall resistance to helminth infection (Dharmarajan et al. 2005).

The present study and that from the Nehru Zoological Park, Hyderabad (Suresh et al. 2001) show the prevalence of intestinal parasites was higher in females than males, contradicting the general trend reported for mammals (Poulin 1996; Schalk \& Forbes 1997). Such trends among captive elephants could be related to the more social nature of females with frequent physical contacts to various age-sex classes compared to males, and hence more susceptibility to parasitic infection. Besides the above reason, the lesser mobility of female elephants compared to males, observed during the course of grazing in natural habitats at the timber camps in the forest department system (Vanitha 2007), resulted in the same space being more frequently used by females than males. In comparison to free ranging elephants, such a constraint imposed by captivity could also contribute to the higher prevalence of parasitic infection among females. The observed higher $(80 \%)$ proportion of females with parasitic prevalence at timber camps is in line with the above statement.

In general, wildlife medicine has received less interest in India when compared to the western world, and the situation is the same with regard to captive elephant health care (Krishnamurthy \& Wemmer 1995; Bist 2002; Vanitha 2007). Lack of clinical facilities with appropriate equipment and financial constraints contribute to inadequate veterinary care in all the captive elephant management systems. The situation is more prominent in private and temple systems, as shown by data on the proportion of elephants receiving veterinary care in the three systems in this study, and elsewhere (Krishnamurthy 1998; Bist et al. 2002; Vanitha 2007). Therefore, due to a lack of exercise, quality and quantity of food, and other appropriate husbandry practices along with inadequately trained veterinary support, elephants in the temple and private systems experience more major health problems (like arthritis, foot rot, skin diseases, overweight and underweight) than the elephants in the forest department system (Vanitha 2007), and this needs immediate redressal. Overall, the study shows that the prevalence of intestinal parasites is higher (i) in cases of captive elephants managed by the forest department in social groups within natural habitats shared with wild conspecifics than those solitarily managed in private and temple facilities, (ii) during summer and monsoon when compared to the winter season, and (iii) among females than males. Therefore, the study suggests more frequent diagnosis and deworming for the forest department captive elephants, especially those managed at the timber camps of Mudumalai and Anamalai wildlife sanctuaries, during summer and monsoon seasons.

\section{REFERENCES}

Arunachalam, K., M. Raman \& T.J. Harikrishnan (2007). Incidence of helminth ova in Indian elephants Elephas 
Appendix 1. List of temple elephants from different places of Tamil Nadu examined for intestinal parasites

\begin{tabular}{|c|c|c|}
\hline & Elephant name & Place and District \\
\hline 1 & Abaiyambal & Mayiladuthurai, Nagapattinam \\
\hline 2 & Abirami $^{+}$ & Thirukkadaiyur, Nagapattinam \\
\hline 4 & Andal & Azhagar Koil, Madurai \\
\hline 5 & Andal & Srirangam, Tiruchirapplli \\
\hline 6 & Ankaiyarkanni+ $^{+}$ & Madurai \\
\hline 3 & Athinayagi & Alwarthirunagari, Tuticorin \\
\hline 7 & Avai $^{+}$ & Thiruperunkundram, Madurai \\
\hline 8 & Bavani & Rameswaram \\
\hline 9 & Boomadevi & Uppiliappan Koil, Thanjavur \\
\hline 10 & Chooligambal & Thirupugalur, Thiruvarur \\
\hline 11 & Dharmambal & Thiruvaiyaru, Thanjavur \\
\hline 12 & Durga & Swamimalai, Thanjavur \\
\hline 13 & Gomathi & Thiruvidaimaruthur, Thanjavur \\
\hline 14 & Kalyani & Perur, Coimbatore \\
\hline 15 & Kasturi & Palani, Dindugul \\
\hline 16 & Kothai & Sriperumpathur, Kanchipuram \\
\hline 17 & Kumuthavalli & Thirukkolur, Tuticorin \\
\hline 18 & Kurunkudinachiyar & Thirukurunkudi, Tirunelveli \\
\hline 19 & Lakshmi & Rettai Thirupathi, Tuticorin \\
\hline 20 & Lakshmi $^{+}$ & Malaikottai, Tiruchirappalli \\
\hline 21 & Maduravalli & Madurai \\
\hline 22 & Mangalam & Kumbakaonam, Thanjavore \\
\hline 23 & Mariyappam & Samayapuram, Tiruchirapplli \\
\hline 24 & Masiniyamma $^{+}$ & Thiruverkadu, Thiruvallur \\
\hline 25 & Muthulakshmi & Perungulam, Tuticorin \\
\hline 26 & Parvathy $^{+}$ & Madurai \\
\hline 27 & Rajeswari $^{+}$ & Salem \\
\hline 28 & Rowthilakshmi & Peraiyur, Madurai \\
\hline 29 & Rukku & Thiruvannamalai \\
\hline 30 & Sengamma & Mannargudi, Thiruvarur \\
\hline 31 & Shanthi & Thiruchendur, Tuticorin \\
\hline 32 & Sivakami $^{+}$ & Tiruppattur, Sivaganga \\
\hline 33 & Sornavalli+ & Kalaiyar Koil, Sivaganga \\
\hline 34 & Subbulakshmi ${ }^{+}$ & Kundrakudi, Sivaganga \\
\hline 35 & Sumathi $^{+}$ & Palani, Dindugul \\
\hline 36 & Valli & Thiruthani, Thiruvallur \\
\hline 37 & Vedanayagi & Bhavani, Erode \\
\hline 38 & Vellaiyammal $^{+}$ & Thanjavur \\
\hline
\end{tabular}

+ indicates infected individual
Appendix 2. List of private elephants from different places of Tamil Nadu examined for intestinal parasites

\begin{tabular}{|c|c|c|}
\hline & Elephant name & Place/District \\
\hline 1 & Ambika $^{+}$ & Swamimalai, Thanjavur \\
\hline 2 & Ammukutti & Srirangam, Tiruchirapplli \\
\hline 3 & Beham $^{+}$ & Madurai \\
\hline 4 & Eswari & Srirangam, Tiruchirapplli \\
\hline 5 & Faseela & Srirangam, Tiruchirapplli \\
\hline 6 & Fathima & Nagur, Nagapattinam \\
\hline 7 & Geethavalli & Peraiyur, Madurai \\
\hline 8 & Gulabhi & Kumbakonam, Thanjavur \\
\hline 9 & Gulebahawali & Venkatachalapuram, Madurai \\
\hline 10 & Indra & Palani, Dindugul \\
\hline 11 & Jaini & Kadayanallur, Madurai \\
\hline 12 & Jothi & Tuticorin \\
\hline 13 & Kamala $^{+}$ & Samayapuram, Tiruchirapplli \\
\hline 14 & Kushma & Madurai \\
\hline 15 & Lakini $^{+}$ & Padavedu, Tiruvannamalai \\
\hline 16 & Lakshmi & Coimbatore \\
\hline 17 & Lakshmi $^{+}$ & Palani, Dindugul \\
\hline 18 & Lakshmi $^{+}$ & Salem \\
\hline 19 & Lakshmi $^{+}$ & Madurai \\
\hline 20 & Lakshmi Priya & Madurai \\
\hline 21 & Malolan & Tambaram, Kanchipuram \\
\hline 22 & Meenakchi & Kodumudi, Erode \\
\hline 23 & Mohan Prasad ${ }^{+}$ & Thirvidaimaruthur, Thanjavur \\
\hline 24 & Nalan & Dharmapuram, Nagapattinam \\
\hline 25 & Periyanayagi & Vaitheswaran Koil, Nagapattinam \\
\hline 26 & Prasanna $^{+}$ & Chennai \\
\hline 27 & Seetha & Thallakulam, Madurai \\
\hline 28 & Shiyamala $^{+}$ & Swamimalai, Kumbakonam \\
\hline 29 & Sita & Srirangam, Tiruchirappalli \\
\hline 30 & Sulochana $^{+}$ & Viruthunagar \\
\hline 31 & Suma & Srirangam, Tiruchirappalli \\
\hline 32 & Sumathi & Venkatachalapuram, Madurai \\
\hline 33 & Sumithra & Samayapuram, Tiruchirapplli \\
\hline 34 & Thulari & Madurai \\
\hline 35 & Vijayan & Samayapuram, Tiruchirapplli \\
\hline
\end{tabular}

+ indicates infected individual 
maximus at Theppakadu Nilgiris, Tamil Nadu. Zoos' Print Journal 22(11): 2898-2899.

Begon, M. \& R.G. Bowers (1995). Beyond host-pathogen dynamics, pp. 478-509. In: Grenfell, B.T. \& A.P. Dobson, (eds.). Ecology of Infectious Diseases in Natural Populations. Cambridge, Cambridge University Press.

Bist, S.S. (2002). An overview of elephant conservation in India. Indian Forester 128(2): 121-136.

Bist, S.S., J.V. Cheeran, S. Choudhury, P. Barua \& M.K. Misra (2002). The domesticated Asian Elephants in India, pp. 129-148. In: Giant in our Hands. Proceedings of the International workshop on the domesticated Asian Elephants. Bangkok, Thailand, February 2001.

Chandrasekharan, K., K. Radhakrishnan, J.V. Cheeran, K.N. Muraleedharan \& T. Prabhakaran (1995). Review of the incidence, ecology and control of common diseases of Asian Elephants with special reference to Kerala, pp. 439-449. In: Daniel, J.C. \& H.S. Datye (eds.). A Week with Elephants: Proceedings of the International Seminar on the Conservation of Asian Elephant. June 1993; Oxford University Press, Oxford.

Dharmarajan, G. (2000). Epidemiology in wild and domestic herbivores at the Mudumalai Wildlife Sanctuary, Tamil Nadu. M.V.Sc Thesis submitted to Tamil Nadu University of Veterinary and Animal Sciences, Chennai, Tamil Nadu, $75 \mathrm{pp}$.

Dharmarajan, G., M. Raman \& M.C. John (2005). Effect of season on helminth loads of wild herbivores and cattle in the Mudumalai Wildlife Sanctuary, southern India. Zoos Print Journal 20(2): 1766-1769.

Dhungel, S., C. Browner \& S. Yoder (1990). Elephant training and management in Nepal. Tigerpaper 17:1-6.

English, A.W. (1979). The epidemiology of equine Strongylosis in southern Queensland 1. The Bionomics of the Free-Living Stages in Faeces and on Pasture. Australian Veterinary Journal 55(7): 299-305.

Hamilton, D.G. \& M. Zuk (1982). Heritable true fitness and bright birds: a role for parasites? Science 218: 384-387.

Holmes, J.C. \& W.M. Bethel (1972). Modification of intermediate host behaviour by parasites. Zoological Jounral of the Linnean Society supplemnt 1: 123-149

Krishnamurthy, V. (1998). Captive elephant management in India under different systems: Present trends. Zoos' Print 13: 1-4.

Krishnamurthy, V. \& C. Wemmer (1995). Veterinary care of Asian timber elephants: Historical accounts and current observations. Zoo Biology 14: 123-133.

Lyles, A.M. \& A.B. Dobson (1993). Infectious disease and intensive management: population dynamics, threatened hosts and their parasites. Journal of Zoo Wildlife Medicine 24: 315-326.

Monson-Bhar, P.E.C. \& D.R. Bell (1982). Manson's Tropical Diseases. English language book society/Bailliere, Tindall, London, xvii+1557pp.

Moore, J. (1984). Parasites that change the behaviour of the hosts. Scientific American 250: 108-115.
Price, P.W., M. Westoby, B. Rice, P.R. Atsatt, R.S. Fritz \& J.N. Thomson (1986). Parasite mediation in ecological interaction. Annual Review of Ecology and Systematics 17: 487-505.

Poulin, R. (1996). Sexual inequalities in helminthic infections: a cost of being male? American Naturalist 147: 287-295.

Rolston, H. (1992). Ethical responsibilities towards wildlife. Journal of American Veterinary Association 200: 618-622.

Saseedran, P.C., S. Rajendran, H. Subramanian, M. Sasikumar, G. Vivek \& K.S. Anil (2003). Incidence of helminthic infection among annually de-wormed captive elephants. Zoos' Print Journal 19(3): 1422.

Schalk, G. \& M.R. Forbes (1997). Male biases of parasitism in mammals: effects of study type, host age and parasite taxon. Oikos 78: 67-74.

Shaw, D.J. \& A.P. Dobson (1995). Patterns of macro-parasite abundance and aggregation in wildlife populations: a quantitative review. Parasitology 111: 111-133.

Sukumar, R., N.V. Joshi \& V. Krishnamurthy (1988). Growth in the Asian Elephants. Proceeding of the Indian Academy of Science. (Animal Science) 97(6): 561-571.

Suresh, K.P., C. Choudhuri, K. Nalini Kumari, Md. Hafeez \& P.A. Hamza (2001). Epidemiological and clinicotherapeutic studies of strongylosis in elephants. Zoos' Print Journal 16(7): 539-540.

Vanitha, V. (2007). Studies on the status and management of captive Asian Elephants (Elephas maximus) at Tamil Nadu in southern India. PhD Thesis. Bharathidasan University, Tiruchirapalli, India, 130+xpp.

Vanitha, V., K. Thiyagesan \& N. Baskaran (2008). Food and feeding of captive Asian Elephants (Elephas maximus) in the three management facilities at Tamil Nadu, south India. Journal of Scientific Transactions in Environment and Technovation 2(2): 87-97.

Vanitha, V., K. Thiyagesan \& N. Baskaran (2009). Socioeconomic status of elephant keepers and human-captive elephant conflict: A case study from three management systems from Tamil Nadu, southern India. Gajah 30: 8-12.

Vanitha, V., K. Thiyagesan \& N. Baskaran (2010). Demography of captive Asian Elephants (Elephas maximus) in three management systems in Tamil Nadu, India. Journal of the Bombay Natural History Society 107(1): 30-37.

Vidya, T.N.C. \& R. Sukumar (2002). The effect of some ecological factors on the intestinal parasite loads of the Asian Elephant (Elephas maximus) in southern India. Journal of Bioscience 27: 521-528.

Watve, M.G. (1992). Ecology of host-parasite interactions in wild mammalian host community in Mudumalai, southern India. PhD Thesis. Indian Institute of Science, Bangalore, India.

Watve, M.G. (1995). Helminthes parasites of elephant's ecological aspects, pp. 289-295. In: Daniel, J.C. \& H.S. Daty (eds.). A week with elephants: Proceedings of the International Seminar on the Conservation of Asian Elephants. June 1993; Oxford University Press, New Delhi. 
Wesenberg-Lund, C. (1931). Contributions to the development of the Trematoda Digenea. Part I. The biology of the Leucochloridium paradoxum. Kongelige Danske Videnskabernes Biology Selskab 4: 89-142.

Wilson, K., O.N. Bjornstad, A.P. Dobson, S. Merler, G. Poglayen, S.E. Randolph, A.F. Read \& A. Skorping (2002). Heterogeneities in macro-parasite infections: patterns and processes, pp. 6-44. In: Hudson, P.J., A. Rizzoli, B.T. Grenfell, H. Heesterbeek \& A.P. Dobson (eds.). The Ecology of Wildlife Diseases. Oxford University Press, New York, United States, xii+197pp.
Author detail: DR. V. VANITHA is presently an assistant professor in zoology. She obtained her $\mathrm{PhD}$ in 2008 for the study on 'Status and management of captive Asian Elephants in Tamil Nadu, India from Bharathidasan University, Tiruchirapalli. DR. K. THIYAGESAN is an associate professor, working on ornithology and is the research adviser to number of $\mathrm{PhD}$ students. DR. N. BASKARAN is a scientist at the Asian Elephant Research and Conservation Centre, working on wild Asian Elephants across Eastern, and Western Ghats and Eastern Himalaya for more than two decades. His research interest includes behavioural ecology of various mammalian fauna, and assessment of population, habitats, biodiversity and impact of development activities.

Acknowledgements: We thank the Tamil Nadu Forest Department, Hindu Religious Endowment Charity and private elephan owners for permitting this study and providing access to the register of records maintained for the captive elephants. We also thank AVC College for providing laboratory for analyzing the dung samples. We acknowledge the critical comments and inputs by Dr. Guha Dharmarajan, Purdue University, Indiana, U.S.A. and Susan Mikota, DVM, Elephant Care International, Hohenwald, TN, U.S.A. that shaped this manuscript significantly. 